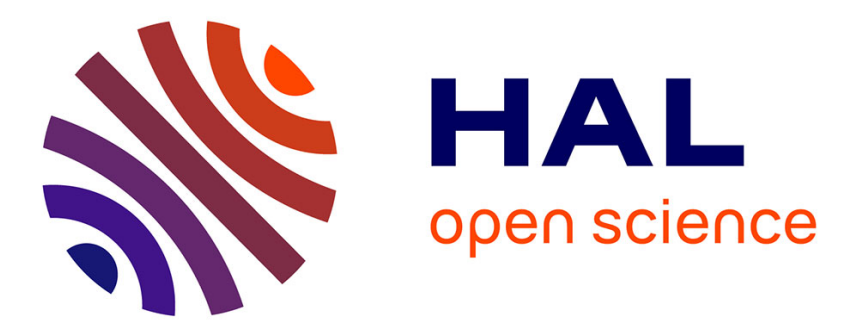

\title{
The nature of the syllabic neighbourhood effect in French
}

S. Mathey, Daniel Zagar, N. Doignon, Alix Seigneuric

\section{To cite this version:}

S. Mathey, Daniel Zagar, N. Doignon, Alix Seigneuric. The nature of the syllabic neighbourhood effect in French. Acta Psychologica, 2006, 123 (3), pp.372-393. 10.1016/j.actpsy.2006.02.003 . hal00561054

\section{HAL Id: hal-00561054 \\ https://u-bourgogne.hal.science/hal-00561054}

Submitted on 26 May 2011

HAL is a multi-disciplinary open access archive for the deposit and dissemination of scientific research documents, whether they are published or not. The documents may come from teaching and research institutions in France or abroad, or from public or private research centers.
L'archive ouverte pluridisciplinaire HAL, est destinée au dépôt et à la diffusion de documents scientifiques de niveau recherche, publiés ou non, émanant des établissements d'enseignement et de recherche français ou étrangers, des laboratoires publics ou privés. 


\title{
The nature of the syllabic neighbourhood effect in French
}

\author{
Stéphanie Mathey, Daniel Zagar, Nadège Doignon, \\ Alix Seigneuric
}

\begin{abstract}
We investigated whether and how sublexical units such as phonological syllables mediate access to the lexicon in French visual word recognition. To do so, two lexical decision task (LDT) experiments examined the nature of the syllabic neighbourhood effect. In Experiments $1 \mathrm{a}$ and $b$, the number of higher frequency syllabic neighbours was manipulated while controlling for the first bigram. The results failed to show a pure syllabic neighbourhood effect. In Experiments $2 a$ and $b$, syllabic neighbourhood and bigram frequency were factorially manipulated. The interaction showed that the syllabic neighbourhood effect was inhibitory when bigram frequency was high, whereas it was facilitatory when bigram frequency was low. Similar patterns of results were found in both the yes/no (Experiments $1 \mathrm{a}$ and 2a) and go/no-go LDTs (Experiments $1 \mathrm{~b}$ and $2 \mathrm{~b}$ ), so varying task requirements of the lexical decision did not influence the effect. These findings are discussed in the context of parallel distributed processing and interactive-activation models, and suggest that orthographic redundancy properties contribute to the influence of phonological syllables.
\end{abstract}

Keywords: Syllable; Visual word recognition; Syllabic neighbourhood; Orthographic redundancy

\section{Introduction}

How is a written word mentally represented and what are the processes underlying lexical access? The basic question of the influence of intermediary reading units situated between the letter representations and the lexical representations is still under debate. Among several possible sublexical units whose influences have been shown empirically, such as syllables (Spoehr \& Smith, 1973; Taft \& Forster, 1976), morphemes (Taft \& Forster, 1975), Basic Orthographic Syllabic Structure (BOSS; Taft, 1979, 1987), body of the BOSS (Taft, 1992), onsets and rimes (Treiman, 1986; Treiman \& Chafetz, 1987), and phonemic features (Lukatela, Eaton, \& Turvey, 2001), phonological syllables have received a great amount of attention. Two main assumptions have been formulated to explain syllable effects in models of visual word recognition. A first hypothesis is that syllables are used as sublexical units that serve as access codes or mediate access to the lexicon (Carreiras, Alvarez, \& De Vega, 1993; Prinzmetal, Treiman, \& Rho, 1986; Spoehr \& Smith, 1973; Taft \& Forster, 1976). This can be accounted for 
by models that explicitly incorporate intermediary units situated between the letter and the word levels (Jacobs, Grainger, Rey, \& Ziegler, 1998; van Heuven \& Dijkstra, 2001). An alternative hypothesis is that syllable effects rather reflect certain redundancy characteristics of the orthographic structure, the co-occurrence of specific letter sequences (Adams, 1981; Seidenberg, 1987). Effects of sublexical units, such as syllables, therefore emerge from distributional properties of letter patterns in the lexicon and are produced implicitly by models with no level of representation corresponding to these sublexical units (Seidenberg \& McClelland, 1989).

The syllable versus orthographic redundancy debate has received a considerable amount of interest in studies using English words in particular. However, in speech perception of English, syllable boundaries are frequently ambiguous and experimental data suggest that syllabifying segmentation is not used (Cutler, Mehler, Norris, \& Segui, 1986) or depends on the stress pattern of the words (Finney, Protopapas, \& Eimas, 1996). Studies investigating the influence of syllables in visual word recognition and speech production have yielded inconsistent results (e.g., Prinzmetal et al., 1986; Rapp, 1992; Seidenberg, 1987; see also Ashby \& Rayner, 2004). Therefore, the role of the syllable or syllable-based structure in English remains an open question. As many authors have pointed out, the use of the syllable as an access code in reading is expected to be more relevant for languages where the syllable structure is less ambiguous than in English. In syllable-timed languages such as French and Spanish, there is less uncertainty about the syllabic boundaries than in stress-timed languages such as English (e.g., Carreiras et al., 1993; Finney et al., 1996; Taft \& Radeau, 1995). In addition, shallow languages such as French and Spanish have more regular correspondences between graphemes and phonemes than deep languages such as English; so phonology may be more activated in reading (Carreiras et al., 1993; Dominguez, de Vega, \& Cuetos, 1997). In the next sections, we review the main evidence for the syllable effect in these two shallow languages. Particular attention is paid to visual word recognition studies that have examined the possible influence of orthographic redundancy, mainly by controlling or manipulating bigram or trigram characteristics. We then introduce the issue of the present study.

\subsection{Syllable effects in French and Spanish}

The relevance of the syllable as a functional sublexical unit for lexical access in French and Spanish has been demonstrated in several studies on speech processing and production. In a seminal study using a fragment detection task in speech perception, Mehler, Dommergues, Frauenfelder, and Segui (1981) reported that French listeners were faster in detecting "pa" in "pa.lace" than in "pal.mier", and also faster in detecting "pal" in "pal.mier" than in "pa.lace". The authors concluded that the syllable is used as a perception unit of speech processing in French (see also Pallier, Sebastian-Gallés, Felguera, Christophe, \& Mehler, 1993; but see Content, Kearns, \& Frauenfelder, 2001; Content, Meunier, Kearns, \& Frauenfelder, 2001). In speech production, evidence from the naming task supports the hypothesis that initial syllables are functional units. Taft and Radeau (1995) reported that nonword pronunciation was influenced by prior presentation of a word prime sharing the first syllable. This is consistent with the priming effect observed by Ferrand, Segui, and Grainger (1996; but see Brand, Rey, and Peereman, 2003) in a naming task using a design similar to that used by Mehler et al. (1981). 
Recently, Carreiras, Ferrand, Grainger, and Perea (2005) showed that the syllable priming effect on word naming times was restricted to the first syllable in French. In Spanish, empirical data have confirmed that syllable units are used in speech perception (Sebastian-Gallés, Dupoux, Segui, \& Mehler, 1992) and speech production (Carreiras et al., 1993; Perea \& Carreiras, 1998). The influence of syllables on pseudoword naming latencies was also found to be restricted to the first syllable (Carreiras \& Perea, 2004a).

A substantial amount of evidence indicates an influence of syllables in Spanish visual recognition. In the lexical decision task (LDT), Carreiras et al. (1993) reported an inhibitory syllable frequency effect on word latencies, even when bigram frequency was controlled. However, the syllable frequency effect was attenuated by holding the bigram frequency constant. For nonword stimuli, no bigram frequency effect was found, while a reliable syllable frequency effect was observed. The inhibitory effect of syllable frequency was higher in hig frequency bigram nonwords (62ms) than in low frequency bigram nonwords (28ms), although the interaction between bigram frequency and syllable frequency failed to reach significance. Further studies have focused on the beginning of the word, by computing either the frequency of the first syllable or the number of words sharing the same first syllables, the syllabic neighbours. Perea and Carreiras (1998) found that these two factors correlate. A regression analysis indicated that the inhibitory effect of the first syllable frequency on lexical decision times was attributable to higher frequency syllabic neighbourhood (HFSN) (see also Alvarez, Carreiras, \& Taft, 2001). Recently, the inhibitory effect of HFSN was replicated with a progressive demasking task, while an eye movement study revealed facilitation from HFSN in early measures only (Carreiras \& Perea, 2004b). When ERPs were recorded in an LDT, a modulation of the N400 amplitude depending on the frequency of the first syllable was found (Barber, Vergara, \& Carreiras, 2004).

The studies that have investigated the influence of syllables in visual recognition of French words have also focused on the beginning of the word. However, the results have led to controversial conclusions. Rouibah and Taft (2001) failed to find a syllabic structure influence in a fragment judgement task and in an LDT in which syllables were marked by two different colours. On the contrary, results from a visual version of the Mehler et al.'s (1981) task provided evidence in favour of the syllable as a functional sublexical unit (Colé, Magnan, \& Grainger, 1999). In the LDT, Mathey and Zagar (2002) found an inhibitory influence of HFSN on French words, which replicated initial findings on Spanish words (Perea \& Carreiras, 1998), even when the orthographic neighbourhood was controlled. Finally, Doignon and Zagar (2005) used the illusory conjunction paradigm (Prinzmetal et al., 1986) to test the respective influence of syllable and orthographic redundancy on the perception of reading units. Bisyllabic words were briefly presented in two colours and the participants had to report the colour of a central target letter. The colour presentation was either congruent or not with syllable segmentation. Illusory conjunctions corresponded to incorrect combinations of colours and letters. The stimulus words had congruent or conflicting syllable and bigram boundaries. The bigram boundaries were defined according to a bigram trough, i.e. a drop in the bigram frequency (see Seidenberg, 1987). The authors found an interaction between the syllable and bigram boundary congruence and the type of presentation. Thus, the influence of syllables was modulated by orthographic redundancy properties. Particularly, the syllable effect was attenuated or even cancelled when the syllable boundary did not exactly match the bigram boundary. The authors concluded that 
both phonological and orthographic factors participate in the perception of sublexical units of reading.

Results from primed LDTs provided additional evidence in favour of the syllable as an important sublexical unit for lexical access in Spanish. Carreiras and Perea (2002) found that syllabic priming was inhibitory when the target word (e.g., BONO) was preceded by a HFSN word prime (e.g., boca) compared to an unrelated word prime (e.g., caja), while it was facilitatory when the same target word was preceded by a nonword syllabic prime (e.g., bopa) compared to an unrelated nonword prime (e.g., caya). Using nonword primes, the authors also compared bisyllabic to monosyllabic target words in order to disentangle the syllabic effect from an orthographic one. No priming effect from the first bigram was observed in the control monosyllabic condition, so facilitation from syllabic neighbour nonword primes was not attributable to the first two letters. Alvarez, Carreiras, and Perea (2004) consistently reported facilitatory syllabic priming from nonword primes. The syllabic neighbourhood advantage on priming was also found in a "pure phonological" condition in which the prime and target did not share the same letters but shared only the same pronunciation.

On the contrary, when word primes were used in the LDT, Dominguez et al. (1997) clearly found an influence of both syllables and orthographic redundancy. The prime and the target words shared the first syllable (e.g., norma/NORTE), the three initial letters (e.g., noria/NORTE) or were unrelated. When the frequency difference between prime and target words was high, a reliable inhibitory priming effect was found with syllabic neighbours (59ms) but not with Wrst-trigram neighbours $(15 \mathrm{~ms})$. This effect was replicated with pseudoword primes, which is consistent with further findings (Alvarez et al., 2004; Carreiras \& Perea, 2002). Interestingly, when the frequency difference between prime and target words was small, a reliable inhibitory priming effect was observed from the two related conditions that did not differ significantly for syllabic neighbours $(54 \mathrm{~ms})$ and first-trigram neighbours (48ms). This provides support for the view that letter co-occurrence participates in lexical access processes.

Finally, only a few studies have used primed LDTs in French. When they used the same stimuli that produced a syllabic priming effect in the naming task, Ferrand et al. (1996) failed to replicate the results in the LDT with a very short prime duration (29ms). However, Carreiras et al. (2005) recently found a syllabic priming effect in the LDT with a longer prime duration (59ms) and revealed that only the first syllable overlap, and not the second, produced facilitation in word decision times. In sum, there is clear evidence now in favour of the influence of syllables in reading Spanish words. This effect cannot be attributed to bigram properties because it was observed even when the bigram factor was controlled. However, there is some evidence to suggest that bigram or trigram properties might contribute to syllable effects (Carreiras et al., 1993; Dominguez et al., 1997). In French, experiments on visual recognition of French words have provided less consistent results in favour of the syllable hypothesis. However, the data from Doignon and Zagar (2005) also suggest that orthographic redundancy might participate in syllable effects. It should be noted that different procedures and materials have been used, but none of them manipulated conjointly syllabic neighbourhood, which is a strong indicator of the use of syllabic structure (see Perea \& Carreiras, 1998), and orthographic redundancy characteristics (Seidenberg \& McClelland, 1989). Therefore, more research is necessary before ruling out the hypothesis that syllable effects are sensitive or partly attributable to orthographic properties. 


\subsection{Aim of the study}

The aim of the present study was to further explore the influence of syllable units and to investigate whether it might be related to orthographic redundancy in visual word recognition of French words. Specifically, the syllabic neighbourhood effect and its relation to bigram properties were examined in LDT experiments. HFSN was computed for the first syllable (see Perea \& Carreiras, 1998) and the first bigram of the word was taken into account. We have focused on the beginning of the word as it has been shown to play a special role in visual word recognition (see Alvarez, Carreiras, \& de Vega, 2000; Carreiras et al., 2005; Taft \& Forster, 1976).

By comparing bisyllabic words with monosyllabic control words, Experiments $1 \mathrm{a}$ and $\mathrm{b}$ examined whether the effect of HFSN might be attributed to the first bigram characteristics. Experiments $2 a$ and $b$ were designed to disentangle the potential influence of HFSN and first bigram frequency in bisyllabic words. The numbers of higher frequency neighbours computed for the first syllable and for the first bigram were factorially crossed. A yes/no LDT was used in Experiments $1 \mathrm{a}$ and $2 \mathrm{a}$, whereas a go/no-go LDT was used in Experiments $1 \mathrm{~b}$ and $2 \mathrm{~b}$ in order to examine whether the results depend on the processing demands of the task (see Perea, Rosa, \& Gomez, 2002).

\section{Experiment 1a}

The aim of Experiment 1a was to test whether the effect of HFSN in French can be explained by a confound with orthographic properties. Bisyllabic words with few syllabic neighbours were compared with bisyllabic words with many syllabic neighbours. These two conditions were matched with two control conditions made up of monosyllabic words sharing the same first bigram. If there is a true syllabic neighbourhood effect and no bigram influence, then an inhibitory effect of HFSN should be found for the polysyllabic words only. No difference should be observed between the two monosyllabic conditions. Thus, an interaction between HFSN and the number of syllables was expected.

\subsection{Method}

\subsubsection{Participants}

Fifty-three psychology students at the University of Burgundy participated in this experiment for course credit. All were native French speakers and reported having normal or corrected-to-normal vision. 
Table 1

Characteristics of the word materials used in experiments $1 \mathrm{a}$ and $\mathrm{b}$

\begin{tabular}{|c|c|c|c|c|c|c|}
\hline \multirow[t]{2}{*}{ Item category } & \multirow[t]{2}{*}{ Example } & \multicolumn{5}{|c|}{ Variable } \\
\hline & & HFSN & HFBN & HFN & $N$ & $F$ \\
\hline \multicolumn{7}{|l|}{ Bisyllabic words } \\
\hline Low HFSN & MICRO & 0 & 5.42 & 0 & 2.17 & 1.11 \\
\hline High HFSN & COLIS & 14.67 & 10.67 & 0 & 3.42 & 0.86 \\
\hline \multicolumn{7}{|l|}{ Monosyllabic words } \\
\hline Control Low HFSN & MINCE & 0 & 3.75 & 0 & 3.50 & 1.36 \\
\hline Control High HFSN & COQUE & 0 & 8.17 & 0 & 6.50 & 1.07 \\
\hline \multicolumn{7}{|c|}{ Syllabic structure $\times$ HFSN $p$ values } \\
\hline & - & $p<.05^{\mathrm{a}}$ & $\mathrm{ns}$ & - & $\mathrm{ns}$ & ns \\
\hline
\end{tabular}

Note: $\mathrm{HFSN}=$ number of higher frequency syllabic neighbours, HFBN = number of higher frequency firstbigram neighbours, HFN = number of higher frequency orthographic neighbours, $N=$ number of orthographic neighbours, $F=$ word frequency per million (in logarithms), ns = non-significant.

a This interaction reflects the way the materials were selected (the variation of HFSN was relevant for bisyllabic words only as monosyllabic words have no syllabic neighbours).

\subsubsection{Materials}

Forty-eight 5-letter words with low frequencies were selected from the French lexical database Lexique (New, Pallier, Ferrand, \& Matos, 2001). Details of the word materials are presented in Table 1. Half of the words were bisyllabic, and the other half were monosyllabic. The bisyllabic word set was divided according to HFSN. The number of syllabic neighbours was computed for the first syllable from the set of bisyllabic 5-letter words in the Lexique database. Half of the bisyllabic words demonstrated a high HFSN (e.g., co.lis) and the other half a low HFSN (e.g., mi.cro). The monosyllabic word set was constructed to serve as a baseline sharing the same first bigram against which to measure the "true" effect of HFSN. More precisely, each bisyllabic word was matched with a monosyllabic word that shared the first bigram (e.g., co.liscoque, mi.cro-mince). In this way, two control conditions of monosyllabic words were constructed that were also matched in length, orthographic neighbourhood and frequency with the two bisyllabic word conditions. No word had any higher frequency orthographic neighbour. To ensure the proper matching of the items, the $p$-values corresponding to the test of the interaction between syllabic structure and HFSN were computed for each controlled variable. As shown in Table 1, no interaction was found significant except for the HSFN variable that was used to design the experimental conditions. Forty 5-letter words were added as fillers. Eightyeight 5-letter nonwords were added for the requirements of the task. All nonwords were orthographically legal and pronounceable in French.

\subsubsection{Procedure}

The participants performed a standard LDT. Stimuli were presented in isolation in the centre of the screen of a personal computer. A central fixation point was presented for $600 \mathrm{~ms}$, followed by the stimulus in lowercase letters. The stimulus remained on the screen until the participants responded. They had to decide whether the letter string was a word or not by pressing a YES or 
NO response key. YES answers were given with the dominant hand and NO answers with the other hand. There was a $2000 \mathrm{~ms}$ inter-trial interval. The participants were also instructed to respond as rapidly and as accurately as possible. Visual feedback was provided when they failed to respond. All participants performed 14 practice trials. They then received the experimental trials in a different random order for each participant.

Table 2

Mean correct response times (RT) with standard errors (in parentheses) and percentage of errors (\% Err) as a function of syllabic structure and higher frequency syllabic neighbourhood (HFSN) for words in Experiment la

\begin{tabular}{llllll}
\hline Words & \multicolumn{2}{l}{ Bisyllabic } & & & Monosyllabic \\
\cline { 2 - 3 } \cline { 6 - 6 } & Low HFSN & High HFSN & & Control Low HFSN & Control High HFSN \\
\hline RT (in ms) & $606(7)$ & $617(6)$ & & $595(7)$ & $610(6)$ \\
$\%$ Err & 4.09 & 9.43 & 4.56 & 5.19 \\
\hline
\end{tabular}

Note: The means and standard errors are computed over participants.

\subsection{Results and discussion}

The mean correct lexical decision times (RTs) and mean error rates averaged over participants for words are presented in Table 2. To avoid the influence of outliers, all RTs more than 2.0 standard deviations above or below the participant mean were removed $(4.87 \%$ of the word correct data). The data were submitted to separate analyses of variance on the participant means $(F 1)$ and on the item means (F2) with Syllabic Structure (monosyllabic vs. bisyllabic) and HFSN (low vs. high) as within-participant and between-item factors.

Analysis of the word reaction times showed that the main effect of HFSN was only significant in the participant analysis, F1(1, 52)D14.72, $p<.001$, and F2(1, 44)D1.64, $p>$.10. HighHFSN words were responded to $14 \mathrm{~ms}$ slower than low-HFSN words. The main effect of the number of syllables was also significant in the participant analysis, $F 1(1,52) D 6.84, p<.05$, but $F 2<1$. Participants took $10 \mathrm{~ms}$ longer to respond to bisyllabic words than to monosyllabic words. More importantly, the interaction between HFSN and the number of syllables was not reliable, $F 1<1$ and $F 2<1$. The effect of HFSN was not larger for bisyllabic words (11ms) than for monosyllabic words (15ms).

An analysis of variance on the error data indicated that the main effect of HFSN was only signiWcant in the participant analysis, F1(1, 52)D9.27, $p<.01$, and F2(1, 44)D2.37, p>.10. HighHFSN words were responded to with more errors (2.99\%) than low-HFSN words. The main effect of the number of syllables was also significant in the participant analysis, F1(1, 52)D4.82, $p<.05$, but $F 2<1$. Bisyllabic words generated an average of $1.89 \%$ more errors than monosyllabic words. The interaction between HFSN and the number of syllables was significant in the participant analysis, $F 1(1,52) D 7.68, p<.01$, but $F 2(1,44) D 1.48, p>.10$. The effect of HFSN was larger in bisyllabic words $(5.35 \%)$ than in monosyllabic words $(1.23 \%)$.

Thus, the present data showed the main effects of HFSN and the number of syllables that were reliable only in the participant analysis. Concerning the HFSN influence, an inhibitory effect on French word recognition was found, as already reported by Mathey and Zagar (2002). The inhibitory influence of increasing the number of syllables is also consistent with recent 
findings from Ferrand and New (2003) on French words of low frequencies. The most important finding of this experiment is that we failed to observe any interaction between HFSN and the number of syllables in the RT analysis. A significant interaction was only found in the byparticipants error analysis. However, if the syllabic neighbourhood effect was purely phonological and only due to syllable representations in French, an interaction should also have been found in the RT data. The present findings therefore suggest that the inXfluence of syllabic neighbourhood was confounded with the influence of the first bigram. It would seem as if there was an effect due to the number of words sharing the first bigram, which would explain why no HFSN difference was observed between the two conditions of monosyllabic and bisyllabic words. In order to test this assumption, an analysis of covariance was run on the word RTs. The interaction remained non-significant when the number of higher frequency bigram neighbours was controlled for $(F 2<1)$. The main effects of HFSN and the number of syllables also remained non-significant $(F 2<1)$.

Taken together, the present data argue against the hypothesis of a pure phonological influence of syllables. They also indicate that a pure orthographic redundancy explanation based on the first bigram neighbours cannot explain the results. On the contrary, the data suggest that the first bigram might contribute to the effect of first-syllable neighbours, at least in the French language. Thus, the syllable effect might be partly due to the frequency of co-occurrence of letter patterns. Because these data seem potentially important for modelling visual word recognition processes, we decided to replicate our findings by means of a go/no-go LDT.

\section{Experiment 1b}

According to Perea et al. (2002), the yes/no and the go-no/go versions of the LDT involve different processing demands. The go/no-go task is said to result in faster reaction times and fewer response errors than the yes/no task because fewer processing resources are necessary. The aim of Experiment $1 \mathrm{~b}$ was to determine whether the results from Experiment $1 \mathrm{a}$ depend on the specific procedure of the LDT. In particular, it seemed important to check whether or not an interaction can be observed between HFSN and the number of syllables while decreasing the processing demands of the LDT.

\subsection{Method}

\subsubsection{Participants}

Sixty-one psychology students at the University of Burgundy participated in this experiment for course credit. All were native French speakers and reported having normal or corrected-to-normal vision. None of them had participated in Experiment 1a.

\subsubsection{Materials}

The words and pseudowords from Experiment 1a were used. 


\subsubsection{Procedure}

The procedure was the same as in Experiment 1a except that the participants performed a go-no go LDT. They were instructed to press a response key with their dominant hand when the letter string was a French word. They were asked to refrain from responding when it was not.

Table 3

Mean correct response times (RT) with standard errors (in parentheses) and percentage of errors ( $\%$ Err) as a function of syllabic structure and higher frequency syllabic neighbourhood (HFSN) for words in Experiment $1 \mathrm{~b}$

\begin{tabular}{llllll}
\hline Words & \multicolumn{2}{l}{ Bisyllabic } & & & Monosyllabic \\
\cline { 2 - 3 } & Low HFSN & High HFSN & & Control Low HFSN & Control High HFSN \\
\hline RT (in ms) & $583(7)$ & $596(7)$ & & $575(6)$ & $591(7)$ \\
\% Err & 0.14 & 4.51 & & 0.68 & 0.41 \\
\hline
\end{tabular}

Note: The means and standard errors are computed over participants.

\subsection{Results and discussion}

The mean correct RTs and mean error rates averaged over participants for words are presented in Table 3. To avoid the influence of outliers, all RTs more than 2.0 standard deviations above or below the participant mean were removed ( $8.11 \%$ of the data). The data were submitted to separate analyses of variance on the participant means $(F 1)$ and on the item means (F2) with Syllabic Structure (monosyllabic vs. bisyllabic) and HFSN (low vs. high) as within-participant and between-item factors.

Analysis of the word reaction times showed a reliable main effect of HFSN only in the participant analysis, F1(1,60)D11.92, $p<.01$, and F2(1, 44)D2.04, p>.10. Low-HFSN words were responded to $15 \mathrm{~ms}$ faster than high-HFSN words. The main effect of the number of syllables was not significant, $F 1(1,60) D 2.75, p>.10$, and $F 2<1$. The interaction between HFSN and the number of syllables was not significant either, both $F 1<1$ and $F 2<1$. The effect of HFSN did not differ between monosyllabic words $(16 \mathrm{~ms})$ and bisyllabic words $(14 \mathrm{~ms})$. Analysis of the error data showed a reliable main effect of HFSN in the participant analysis, $F 1(1,60) D 25.12, p<.001$, but $F 2(1,44) D 2.06, p>.10$. High-HFSN words generated an average of $2.05 \%$ more errors than low-HFSN words. The main effect of the number of syllables was significant in the participant analysis, F1(1, 60)D15.49, $p<.001$, but F2(1,44)D1.29, $p>.10$. Bisyllabic words generated an average of $1.78 \%$ more errors than monosyllabic words. The interaction between HFSN and the number of syllables was also significant in the participant analysis, F1(1,60)D36.62, $p<.001$, but F2 $(1,44) D 2.21, p>.10$. An inhibitory effect of HFSN was observed in the bisyllabic words (4.37\%) but not in the monosyllabic words ( $i 0.28 \%)$.

The present data from the go/no-go LDT replicated those from Experiment 1a using the yes/no LDT. The main effects of number of syllables and HFSN were significant in the participant analysis. These results are consistent with other studies in French (Ferrand \& New, 2003; Mathey \& Zagar, 2002). However, they again failed to reach significance in the item analysis. We will come back to this lack of significance in the item analysis in the discussion of Experiment 2a. 
More importantly, there was still no interaction between HFSN and the number of syllables in the RT analysis. This lack of interaction remained when the number of higher frequency first bigram neighbours was controlled for in a covariance analysis $(F 2<1)$, as was also the case for the main effects of HFSN and the number of syllables $(F 2<1)$.

The results of Experiments $1 \mathrm{a}$ and $1 \mathrm{~b}$ suggest that the effect of first-syllable neighbours might not be completely independent from the first bigram influence in French. This is consistent with a recent study from Doignon and Zagar (2005) showing that illusory conjunction errors in French were affected by both syllable and bigram information. Finally, the present data are also consistent with findings from the Spanish language showing similar priming with syllabic and first-trigram neighbours (Dominguez et al., 1997), and also with data showing that the control for bigram frequency decreased the syllabic neighbourhood effect (Carreiras et al., 1993). Therefore, at this point, it seems necessary to examine systematically the joint influence of the first syllable and first bigram on visual word recognition with new materials. Experiment 2 was designed for this purpose.

\section{Experiment $2 a$}

The aim of Experiment $2 a$ was to disentangle the potential influence of syllabic neighbourhood and orthographic redundancy. More precisely, the influence of first-syllable and first-bigram frequency was examined by manipulating the number of higher frequency words sharing the first syllable, the syllabic neighbours, and the number of words sharing the first bigram, hereafter referred to as first-bigram neighbours. These two factors were factorially crossed. The recent data from Doignon and Zagar (2005) using the illusory conjunction paradigm showed that the phonological influence of syllables on word perception was modulated by bigram frequencies. Based on this result, an interaction between HFSN and higher frequency first-bigram neighbourhood (HFBN) was expected. If the inhibitory syllabic neighbourhood effect is sensitive to orthographic redundancy, this effect should increase when the number of first-bigram neighbours of higher frequency increases.

\subsection{Method}

\subsubsection{Participants}

Fifty-two psychology students at the University of Burgundy participated in this experiment for course credit. All were native French speakers and reported having normal or corrected-to-normal vision. None of them had participated in the previous experiments.

\subsubsection{Materials}

Seventy-two bisyllabic words of low frequency were selected from the French lexical database Brulex (Content, Mousty, \& Radeau, 1990). They were 5- to 8-letters long. Details of the word materials are presented in Table 4. The number of higher frequency syllabic neighbours and the number of higher frequency first-bigram neighbours were factorially crossed. First-bigram neighbours refer to the words sharing the same first bigram in the whole 
set of bisyllabic words in the Brulex database. The syllabic neighbours were computed in the Brulex database according to a syllabification algorithm based on a consonanticity scale where the syllable onset is determined as the peak of consonanticity (Klein, 1993).1 In total, 36 words with a high HFSN (e.g., car.nage; cla.vier) were compared with 36 words with a low HFSN (e.g., cap.ture; clo.cher). Half of them had a high HFBN (e.g., capture; carnage), and the other half had a low HFBN (e.g., clocher; clavier). In this way, words were matched according to their first bigram across the syllable conditions.

Table 4

Characteristics of the word materials used in Experiments 2a and b

\begin{tabular}{|c|c|c|c|c|c|c|c|c|c|c|c|}
\hline \multirow[t]{3}{*}{ Condition } & \multicolumn{11}{|c|}{ Variable } \\
\hline & \multicolumn{2}{|c|}{ Experimental } & \multicolumn{3}{|c|}{ Controlled } & \multicolumn{6}{|c|}{ Other } \\
\hline & HFBN & HFSN & $\mathrm{F}$ & HFN & $\mathrm{N}$ & Fs1 & Fs2 & $\mathrm{Fbl}$ & $\mathrm{Fb} 2$ & $\mathrm{Fb} 3$ & Flastb \\
\hline \multicolumn{12}{|l|}{ Low $H F B N$} \\
\hline Low HFSN (e.g., clo.cher) & 5.06 & 0.67 & 1.00 & 0 & 0.6 & 0.02 & 0.12 & 0.11 & 0.19 & 0.09 & 0.63 \\
\hline High HFSN (e.g., cla.vier) & 5.00 & 4.44 & 1.06 & 0 & 1.8 & 0.04 & 0.40 & 0.11 & 0.56 & 0.17 & 0.60 \\
\hline \multicolumn{12}{|l|}{ High $H F B N$} \\
\hline Low HFSN (e.g., cap.ture) & 27.50 & 0.72 & 0.87 & 0 & 0.4 & 0.12 & 0.13 & 0.63 & 0.39 & 0.11 & 0.72 \\
\hline \multicolumn{12}{|l|}{ High HFSN (e.g., car.nage) } \\
\hline & 25.67 & 12.11 & 0.98 & 0 & 1.0 & 0.24 & 0.05 & 0.63 & 0.84 & 0.18 & 0.31 \\
\hline $\mathrm{HFSN} \times \mathrm{HFBN} p$ value & ns & $p<.05^{\mathrm{a}}$ & ns & - & ns & ns & $\mathrm{ns}$ & ns & ns & ns & ns \\
\hline
\end{tabular}

Note: HFBN = number of higher frequency first-bigram neighbours, HFSN = number of higher frequency syllabic neighbours, $F=$ word frequency per million (in logarithms), HFN = number of higher frequency orthographic neighbours, $N=$ number of orthographic neighbours, Fsl=frequency of the first syllable per million, Fs $2=$ frequency of the second syllable per million, $\mathrm{Fbl}=$ frequency of the first bigram per million, Fb2= frequency of the second bigram per million, $\mathrm{Fb} 3=$ frequency of the third bigram per million, Flastb $=$ frequency of the last bigram per million, $\mathrm{ns}=$ non-significant.

a This interaction reflects the fact that it was impossible to select words with very high HFSN and low HFBN. However, this pattern is different from the cross-over interaction observed in the LDT results.

For example, the low frequency bigram cl occurred in a target word with a first syllable of low frequency (clo in clocher) matched with a target word with a first syllable of high frequency (cla in clavier). All first syllables were 3 letters long. The number of orthographic neighbours was controlled for and no word had any higher frequency orthographic neighbour. Fifty-three words were added as fillers. One hundred twenty-five nonwords of 5- to 8-letters long were added for the requirements of the task. The nonwords were orthographically legal and pronounceable.

\subsubsection{Procedure}

The participants performed a standard LDT. The procedure was the same as in Experiment 1a.

1 More precisely, the onset corresponds to the consonants whose consonanticity value is three points higher than that of the consonant following immediately. However, if the first consonant, which exhibits the highest consonanticity value, does not differ by at least three points from the following consonant, then the first consonant is defined as the coda of the first syllable, and the second consonant is defined as the onset of the second syllable. 


\subsection{Results and discussion}

The mean correct RTs and mean error rates averaged over participants for words are presented in Table 5. To avoid the influence of outliers, all RTs more than 2.0 standard deviations above or below the participant mean were removed ( $3.56 \%$ of the data). The data were submitted to separate analyses of variance on the participant means $(F 1)$ and on the item means (F2) with HFSN (low vs. high) and HFBN (low vs. high) as within-participant and betweenitem factors. An analysis of variance was run on the word reaction times. The main effect of HFSN was not significant, as $F 1<1$ and $F 2<1$. The main effect of HFBN was only significant in the participant analysis, $F 1(1,51) D 10.19, p<.01$, but $F 2<1$. Low-HFBN words were responded to $14 \mathrm{~ms}$ faster than high-HFBN words.

Table 5

Mean correct response times (RT) with standard errors (in parentheses) and percentage of errors (\% Err) as a function of higher frequency syllabic neighbourhood (HFSN) and higher frequency first-bigram neighbourhood (HFBN) for words in Experiment 2a

\begin{tabular}{llllll}
\hline \multirow{2}{*}{ Words } & \multicolumn{2}{l}{ Low HFBN } & & & \multicolumn{2}{l}{ High HFBN } & \\
\cline { 2 - 3 } \cline { 5 - 6 } & Low HFSN & High HFSN & & Low HFSN & High HFSN \\
\hline RT (in ms) & $619(9)$ & $601(10)$ & & $612(10)$ & $635(12)$ \\
$\%$ Err & 9.72 & 3.44 & 3.44 & 9.22 \\
\hline
\end{tabular}

Note: The means and standard errors are computed over participants.

The HFSNfHFBN interaction was reliable in both the item and the participant analyses, $F 1(1$, 51)D28.99, $p<.001$, and F2 $(1,68) D 4.98, p<.05$. Increasing HFSN was facilitatory when HFBN was low (i18ms), while it was inhibitory when HFBN was high $(+23 \mathrm{~ms})$. An analysis of variance run on the error data provided a similar pattern of results. None of the main effects were significant, $F 1<1$ and $F 2<1$. A reliable HFSNfHFBN interaction was observed, $F 1(1,51) D 82.69, p<.001$, and F2 $(1,68) D 4.51, p<.05$. The effect of increasing HFSN was facilitatory on the error rates when HFBN was low (i6.28\%), while it was inhibitory when HFBN was high (+5.78\%). The important finding of this experiment is that we observed a cross-over interaction between HFSN and HFBN in both the RTs and the error rates, which was reliable in both the participant and item analyses.

The inhibitory influence of HFSN that was previously reported for French and Spanish words presented in the LDT (Mathey \& Zagar, 2002; Perea \& Carreiras, 1998) was observed here only in the high-HFBN condition. A strong inhibitory influence of syllabic neighbourhood was indeed expected in this condition. What was not expected, on the other hand, was that the effect of HFSN was reversed in the low-HFBN condition. It would seem as if syllabic neighbours facilitated visual word recognition when the orthographic redundancy of the beginning of the word was low. As a consequence of the interaction pattern, there was no main effect of either HFSN or HFBN. However, it was not possible to control all factors in the present experiment and a possible bias in the results might be explained by other factors of syllable structure and 
orthographic redundancy. Additional analyses were run to test this possibility. First, as we did not take into account low frequency syllables in the material construction, we computed token frequencies for the first and second syllables (see Table 4). When an analysis of covariance was conducted on the word RTs with first syllable frequency as a covariate, the interaction remained significant, $F 2(1,67) D 4.59, p<.05$. This suggests that lower frequency neighbours cannot explain the results. The interaction remained significant when controlling for the second syllable frequency, F2 $(1,67) D 4.28, p<.05$, which indicates that second syllable characteristics do not influence the data either (see also Carreiras et al., 2005). Second, as we did not take into account first bigram neighbours of lower frequency or any bigram neighbours at the other positions, we have computed token frequencies for the first, second, third and final bigrams (see Table 4) and run additional analyses of covariance on the word RTs. The interaction remained significant after factoring out the first bigram frequency, $F 2(1,67) D 4.92, p<.05$, the second bigram frequency, F2 $(1,67) D 4.79, p<.05$, the third bigram frequency $F 2(1,67) D 5.07$, $p<.05$, and the final bigram frequency $F 2(1,67) D 3.94, p D .05$. This confirmed that the interaction between HFSN and HFBN cannot be explained by other indices of orthographic redundancy based on token frequencies. 2 We also ran an additional analysis of covariance with both the first syllable frequency and the first bigram frequency as covariates. The interaction remained significant, $F 2(1,66) D 5.19, p<.05$ and the adjusted means confirmed that the interaction pattern was unchanged (Low HFBN-Low HFSND629ms; Low HFBN-High HFSND597ms; High HFBN-Low HFSND615ms; High HFBN-High HFSND640ms). Furthermore, the present data might help to explain why the main effect of HFSN was quite small in Experiments $1 a$ and $b$ and also failed to reach significance in the item analysis. The two conditions of monosyllabic and bisyllabic words were strictly matched according to the first bigram, so that HFBN was controlled across the conditions. However, HFBN was not controlled within each word condition, so variability between words was important on the basis of this factor. In the present experiment, we have shown that the direction of the HFSN effect depended on HFBN. Thus, in addition to the small number of items per condition in Experiments $1 a$ and $b$, item variability is a possible explanation for the small effect of HFSN that was not significant in the item analyses of Experiments $1 a$ and b. Before discussing the interaction further, we decided to check whether it could be replicated with the go/no-go version of the LDT and another set of participants.

\section{Experiment 2b}

The pattern of interaction we found between syllabic and first-bigram neighbourhoods in

Experiment $2 a$ was quite surprising. The aim of Experiment $2 b$ was to check if these results could be replicated when task processing demands were reduced by using the go/ no-go version of the LDT. 


\subsection{Method}

\subsubsection{Participants}

Fifty psychology students at the University of Burgundy participated in this experiment for course credit. All were native French speakers and reported having normal or corrected-tonormal vision. None of them had participated in the previous experiments.

\subsubsection{Materials}

The words and nonwords were the same as in Experiment 2a.

\subsubsection{Procedure}

The participants performed a go/no-go LDT. The procedure was identical to that used in Experiment 1b.

\subsection{Results and discussion}

The mean correct RTs and mean error rates averaged over participants for words are presented in Table 6. To avoid the influence of outliers, all RTs more than 2 standard deviations above or below the participant mean were removed $(3.75 \%$ of the data). The data were submitted to separate analyses of variance on the participant means $(F 1)$ and on the item means (F2) with HFSN (low vs. high) and HFBN (low vs. high) as within-participant and betweenitem factors.

An analysis of variance was run on the word reaction times. The main effect of HFSN was significant only in the participant analysis, F1(1, 49)D17.19, $p<.001$, and F2<1. Low-HFSN words were responded to $14 \mathrm{~ms}$ faster than high-HFSN words. The main effect of HFBN was significant only in the participant analysis, F1(1,49)D13.32, $p<.001$, and F2<1. Low-HFBN words were responded to $14 \mathrm{~ms}$ faster than high-HBSN words. The interaction between HFSN and HFBN was reliable, F1(1, 49)D85.82, $p<.001$, and F2 $(1,68) D 5.44, p<.05$. Increasing HFSN produced a facilitatory effect when HFBN was low ( $i 15 \mathrm{~ms})$, while it produced an inhibitory effect when HFBN was high (+42 ms).

2 It also seems diYcult to explain our results in terms of variations of the stress pattern because, contrary to Spanish, French is a language with a fixed accentuation. Bisyllabic words presented in isolation typically have a weak-strong accented pattern (e.g., Ducrot \& Todorov, 1972; Vihman, DePaolis, \& Davis, 1998). 
Table 6

Mean correct response times (RT) with standard errors (in parentheses) and percentage of errors (\% Err) as a function of higher frequency syllabic neighbourhood (HFSN) and higher frequency first-bigram neighbourhood (HFBN) for words in Experiment $2 b$

\begin{tabular}{llllll}
\hline \multirow{2}{*}{ Words } & \multicolumn{2}{l}{ Low HFBN } & & & High HFBN \\
\cline { 2 - 3 } \cline { 5 - 6 } & Low HFSN & High HFSN & & Low HFSN & High HFSN \\
\hline RT (in ms) & $600(9)$ & $585(11)$ & & $585(10)$ & $627(11)$ \\
$\%$ Err & 4.44 & 0.44 & 1.00 & 2.33 \\
\hline
\end{tabular}

Note: The means and standard errors are computed over participants.

An analysis of variance run on the error data showed that the main effect of HFSN was significant only in the participant analysis, F1(1, 49)D15.47, $p<.001$, and F2<1. Low- HFSN words generated an average of $1.33 \%$ more errors than high-HFSN words. The main effect of HFBN was significant only in the participant analysis, F1(1, 49)D6.84, $p<.05$, and $F 2<1$. Low-HFBN words generated an average of $0.77 \%$ more errors than high-HFBN words. The HFSNfHFBN interaction was reliable in the participant analysis, $F 1(1,49) D 38.98, p<.001$, and marginally significant in the item analysis, F2 $(1,68) D 3.07, p D .08$. Increasing HFSN produced a facilitatory effect when HFBN was low (i4.00\%), while it produced a slight inhibitory effect when HFBN was high (+1.33\%). As in Experiment 2a, analyses of covariance were run on the word RTs of Experiment $2 \mathrm{~b}$ in order to check that the interaction was not due to token frequencies of the two syllables. The interaction again remained significant when we controlled for the first syllable frequency, $F 2(1,67) D 5.64, p<.05$, and the second syllable frequency $F 2(1,67) D 4.46$, $p<.05$. Analyses of covariance were also conducted to check that the interaction was not due to orthographic redundancy factors. Again, the interaction remained significant when we controlled for the first bigram frequency, F2 $(1,67) D 5.46, p<.05$, the second bigram frequency, $F 2(1,67) D 5.27, p<.05$, the third bigram frequency, F2 $(1,67) D 5.63, p<.05$ and the final bigram frequency, $F 2(1,67) D 4.24, p<.05$. We also ran an additional analysis of covariance with both the first syllable frequency and the first bigram frequency as covariates. The interaction remained significant, $F 2(1,66) \mathrm{D} 4.30, p<.05$ and the adjusted means confirmed that the interaction pattern was unchanged (Low HFBN-Low HFSND594ms; Low HFBN-High HFSND576ms; High HFBN-Low HFSND591 ms; High HFBN- High HFSND634ms). Thus, the interaction between HFSN and HFBN cannot be explained by these other indices of syllable structure and orthographic redundancy.

On the whole, the data from this experiment replicated those from Experiment 2a while task demand was varied. The most important result is that a reliable interaction between HFSN and HFBN was again observed in both the RT and error analyses. The effect of syllabic neighbourhood was found to be inhibitory in high-HFBN words, replicating previous studies showing an inhibitory influence of syllabic neighbourhood in Spanish (Perea \& Carreiras, 1998) and French (Mathey \& Zagar, 2002). However, the effect was facilitatory in low-HFBN words. These findings suggest that the influence of syllables depends on orthographic redundancy constraints. The way current models of visual word recognition can handle these results is discussed below. 


\section{General discussion}

The aim of the present study was to examine the influence of phonological and orthographic factors on visual recognition of French words with the LDT. The main findings can be summarised as follows. The results of Experiments $1 a$ and $b$ failed to provide clear evidence in favour of a pure influence of syllables. A syllabic neighbourhood factor was manipulated in a bisyllabic-word condition, while a pseudo-syllabic neighbourhood factor based on first-bigram matching was considered in a control condition of monosyllabic words. No interaction was found between syllable structure (monosyllabic vs. Bisyllabic words) or syllabic neighbourhood. These results suggest that letter co-occurrences might participate in the emergence of a syllabic neighbourhood effect in French. In Experiments $2 a$ and $b$, the numbers of syllabic and firstbigram neighbours of higher frequency than the stimulus were factorially manipulated. A reliable interaction was found in both the participant and item analyses, showing that the effect of HFSN was inhibitory when HFBN was high, whereas it was facilitatory when HFBN was low. Similar patterns of results were observed in both the yes/no (Experiments $1 \mathrm{a}$ and $2 \mathrm{a}$ ) and the go/no-go LDTs (Experiments $1 \mathrm{~b}$ and $2 \mathrm{~b}$ ), which suggests that varying task requirements of the LDT did not influence the data. Syllabic neighbourhood influence therefore appears to be related to orthographic redundancy characteristics. In what follows, we compare the present results to the experimental literature of visual recognition of French and Spanish words. We then examine how these data can be interpreted in current models of visual word recognition.

\subsection{Syllable and orthographic redundancy effects}

The results of the present study have shown that the syllabic neighbourhood effect in French depends on orthographic co-occurrence constraints. This strongly suggests that French readers use both syllable units and letter co-occurrence properties before word recognition is achieved. Recently, Doignon and Zagar (2005) advanced a similar argument to account for findings obtained with the illusory conjunction paradigm showing that the syllabic effect was modulated by bigram boundaries in French. The results obtained by Colé et al. (1999) with the visual version of the syllable monitoring technique can also lead to a similar conclusion as target detection was facilitated when orthographic and phonological information were converging. In addition, the hypothesis that orthographic redundancy mediates the activation of phonological syllable units is not in contradiction either with other experiments in French and Spanish showing a syllabic neighbourhood effect when bigram frequency was not controlled (e.g., Mathey \& Zagar, 2002), or with studies showing an effect of the syllabic structure when bigram frequency was controlled (Carreiras et al., 1993; Ferrand \& New, 2003). These studies strongly argue in favour of an infuence of syllables but do not rule out the possible intervention of orthographic redundancy because this factor was not manipulated. Finally, in a primed LDT where the frequency difference between prime and target words was small, Dominguez et al. (1997) found that a similar inhibitory priming effect occurred for both first-syllable and firsttrigram neighbours in Spanish. This finding provides additional support for the view that both phonological and orthographic properties are used at a sublexical level. On the contrary, when nonwords or words of lower frequency than the target were used as primes, no influence of orthographic sublexical factors was observed on the target identification latencies (Alvarez et 
al., 2004; Carreiras \& Perea, 2002; Dominguez et al., 1997). This discrepancy might be attributed to the different procedures that were used and to the different prime types (word vs. nonword) in particular. Further studies with cross-task comparisons are necessary to elucidate this issue.

\subsection{Current models of visual word recognition}

Our results, suggesting that visual word recognition implies the use of both statistical properties of the written language and phonological syllables, have important implications for current models. In the parallel distributed processing (PDP) model (Seidenberg, 1987; Seidenberg \& McClelland, 1989; see Plaut, 1999; for an extension to polysyllabic words), lexical access involves the computation of orthographic and phonological codes. Letter cooccurrences are coded at the orthographic level and participate in visual word recognition processes. This important feature of the model explains facilitation effects from increasing bigram frequency. Another key feature of the model is that it only encodes orthographic redundancy and orthographic-phonological regularities, so that it can simulate effects of syllabic structure while syllables are not represented (Seidenberg, 1987). Effects of syllabic structure can therefore be produced by the frequency of co-occurrence of letter patterns. In addition, the model can account for a pseudosyllable effect on monosyllabic words by means of distributional properties of letter patterns in the lexicon. The data from Seidenberg (1987) showing that monosyllabic words that exhibited a bigram trough pattern produced the same number of illusory conjunctions as bisyllabic words provided support for this hypothesis (but see Rapp, 1992). However, some effects of the syllable structure on visual word recognition remain difficult to explain within the PDP framework. First, the model only predicts facilitation from increasing orthographic redundancy (see Sears, Hino, \& Lupker, 1999). Consequently, if syllable effects are a by-product of orthographic redundancy (Seidenberg, 1987), the model would logically predict facilitation from increasing syllable frequency. In addition, as pointed out by Sears et al. (1999), the model has no means to explain inhibitory effects attributed to lexical competition. Thus, this model would inadequately accommodate the inhibitory effect of HFSN reported in previous studies on Spanish and French words (e.g., Alvarez et al., 2001; Mathey \& Zagar, 2002; Perea \& Carreiras, 1998) and in the participant analysis of Experiments 1a and b. Second, the PDP model does not account for syllable effects that have been shown not to be entirely attributable to a confound with orthographic redundancy, such as the interaction between bigram properties and syllabic information reported in Experiments $2 a$ and $b$ and also previous results found with the illusory conjunction paradigm (Doignon \& Zagar, 2005; Rapp, 1992). As proposed by Rapp (1992), a solution which dissociates orthographic and phonological influence is to incorporate syllabic representations in the model. However, it seems difficult to explain how this modification would help to resolve the first problem we have raised, that is, the inhibition from syllabic neighbourhood. Therefore, altogether, these data seriously challenge the PDP model. The effects of syllable frequency and syllabic neighbourhood reported in French and Spanish word recognition can be more easily accommodated within a dual-route interactive- activation (IA) framework. The IA model (McClelland \& Rumelhart, 1981) was first shown to capture an inhibitory effect of higher frequency orthographic neighbourhood in visual word recognition by means of a lateral inhibition mechanism situated at the word level (e.g., Grainger, O'Regan, Jacobs, \& Segui, 1989). In this model, orthographic neighbour are activated via a direct route 
from letter units to word units. A similar mechanism of lexical inhibition between the activated candidates has been used to account for the inhibitory effect of syllabic neighbourhood that was observed in visual word recognition of Spanish and French words (Alvarez et al., 2004; Carreiras \& Perea, 2002; Dominguez et al., 1997; Mathey \& Zagar, 2002; Perea \& Carreiras, 1998). As claimed by these authors, the general IA model (McClelland \& Rumelhart, 1981) needs to be modified to explain inhibitory syllabic effects in the LDT. Specifically, the model has to incorporate syllables on the phonological route. Syllables are therefore considered as phonological units that mediate between the letter and the word level. When a written word is presented, activation from the corresponding letter units spreads to positional syllable units. Then activation from the syllables spreads to the word level. A cohort of lexical candidates sharing the same positional syllable is activated via the phonological route. These candidates compete with each other by means of a lateral inhibition mechanism in such a way that those that do not exactly match the visual input are eliminated. The consequence of this competition between syllabic neighbours is that the stimulus word recognition is delayed. The use of the two routes is consistent with the absence of interaction between orthographic neighbourhood and syllabic neighbourhood effects that was previously reported (Mathey \& Zagar, 2002). Orthographic neighbourhood effects are attributed to the letter-word route, while syllabic neighbourhood effects are attributed to the phonological route. However, a major limitation of the IA model is that it cannot account for the influence of orthographic redundancy. Thus, additional assumptions need to be formulated in order to explain how the phonological syllabic neighbourhood effect might be related to orthographic redundancy characteristics, as suggested in the present study. More precisely, it remains to be explained why the syllabic neighbourhood effect seems related to the first bigram (Experiments $1 a$ and $b$ ), and more precisely why the effect reversed according to HFBN (Experiments $2 a$ and $b$ ).

\subsection{The IA model with syllables (IAS model)}

As a theoretical framework, we therefore use an extended version of the dual-route IA model incorporating syllables. The IAS model (see Fig. 1) is a one-lexicon model that shares the main features of the general IA model (McClelland \& Rumelhart, 1981) plus two major modifications, adjacent letter connectivity and the representation of phonological syllable units with a resting level based on frequency. The motivation for these additional assumptions is presented below. As can be seen in Fig. 1, two routes allow access to the lexicon in the IAS model. The orthographic route, which is a direct connection between letters and words, is necessary to explain orthographic neighbourhood effects (e.g., Grainger et al., 1989). A bigram inflence can also be accounted for by means of the orthographic route. Indeed, as has already been reported in the literature (for a discussion, see Gernsbacher, 1984), we observed in Experiments $2 a$ and $b$ a slight facilitation from HFBN when HFSN was low. The question is to determine whether such a mild effect can be accounted for by an IA-based model. A first hypothesis is to postulate that bigrams are represented as intermediary units located between the letter and the word level, with a resting level based on frequency. This would fully account for a facilitatory effect of HFBN. 


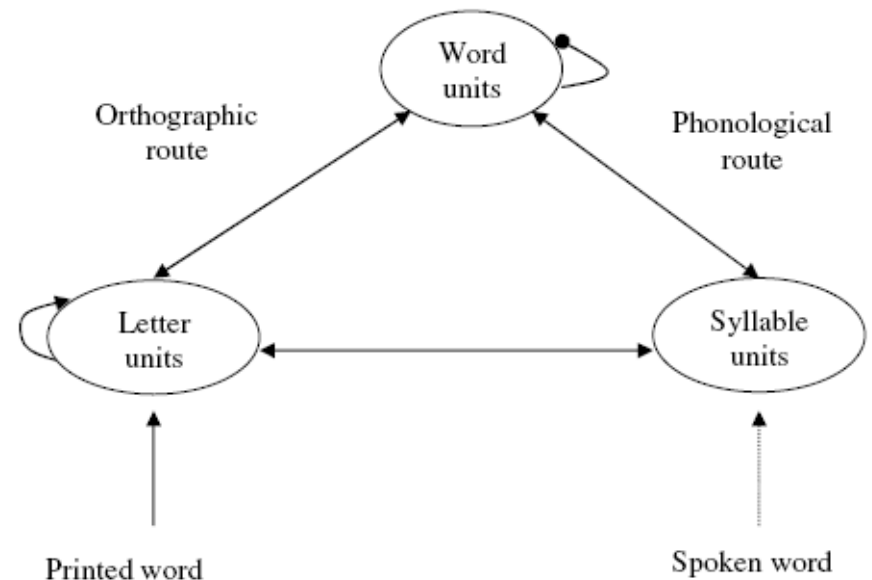

Fig. 1. A visual word recognition model based on interactive activation and incorporating syllables (the IAS model). Syllable units have a resting level based on frequency. Adjacent letters are connected. The activation weight of the first two letters is set higher than that of the remaining letters. The arrows represent facilitatory connections and the dot represents inhibition.

However, Experiments $2 \mathrm{a}$ and $\mathrm{b}$ failed to produce a pure HFBN effect, which leads us to reject this possibility. Following Adams $(1979,1981)$, a second hypothesis is to assume that adjacent letters are connected. In this case, letters are more reactivated when they belong to high frequency bigrams than when they belong to low frequency bigrams (see also PDP models). Thus, facilitation from high frequency bigrams would be observed whatever their serial position. However, no such evidence is available in the literature. On the contrary, bigram and syllable effects were instead reported at the beginning of the word (e.g., Carreiras et al., 2005; Taft \& Forster, 1976). Finally, we propose a third hypothesis which combines Adams' $(1979,1981)$ assumption on connecting letters and the suggestion from Rumelhart and McClelland (1982) to adjust the activation rate of letter units according to serial letter positions. According to this last assumption, the activation weight of the first two letters of a word could be set higher than that of the remaining letters. Thus, when the first two letters of a word belong to a high frequency bigram, they would both produce more activation to the word units and also receive more activation from the word units (because more words were activated) than when they belong to a rare bigram. This accounts for the slight facilitation we observed in Experiments $2 a$ and $b$. We therefore rely on this third hypothesis in the following. In the phonological route, phonological syllables mediate between the levels of the letter and the word (e.g., see Carreiras et al., 1993; Alvarez et al., 2004). The assumption that syllables are functional representations stored in the lexical system is based on speech primacy. In language acquisition, the correspondence between spoken words and meaning is the primary association, orthography being later linked to these pre-existing representations (for a discussion, see Frost, 1998). Because phonological syllables are important functional units in language acquisition, it remains possible to assume that they are also used in skilled reading (see Colé et al., 1999). Furthermore, we assume here that there is a direct connection between letters and phonological syllables that operates in the same way as the letter-word connection of the original IA model. Activation from the letters spreads to consistent positional syllables. Therefore, the initial bigram of a word, such as "co" in "coque", not only activates the syllable /cok/ but also other consistent syllables such as /co/, /cod/, and /cot/ for example. The strength of syllable activation not only depends on the 
amount of activation from the letter level, but also on the syllable resting level. This resting activation level is proportional to syllable frequency. Thus, high-frequency syllables are activated more rapidly than low-frequency ones. Activation from the syllables then spreads to all the consistent words in the lexicon. The target word as well as its syllabic neighbours is therefore activated by means of syllables units. The effect of the syllable units is twofold. First, the syllables produce direct facilitation in activating the target word. Second, they produce indirect inhibition by activating the higher frequency syllabic neighbours. Most of the time, the net effect of syllabic frequency is inhibitory as there is competition between the target and its syllabic neighbours (Perea \& Carreiras, 1998). This interpretation is also consistent with previous findings from ERPs suggesting that the influence of syllables is facilitatory at the beginning of word lexical processing, while lateral inhibition later develops at the word level (Barber et al., 2004). The absence of interaction between mono- and bisyllabic words in Experiments $1 \mathrm{a}$ and $\mathrm{b}$ can be explained in the IAS framework. According to the assumption of connected letters (Adams, 1981), high-frequency bigrams would be more strongly activated than low frequency ones because adjacent letters mutually reinforce each other. Highfrequency bigrams are therefore more strongly activated than low-frequency bigrams and would send more activation to the syllables, therefore activating bisyllabic competitors more strongly than low-frequency bigrams do. This reinforcement of connected adjacent letters explains how a pseudo-syllabic effect can be found in monosyllabic words. Importantly, the model can handle the interaction between HFBN and HFSN found in Experiments $2 a$ and $b$. In the high-HFBN condition, syllables would rapidly receive strong activation from the letter level. Because they receive strong activation from the high frequency bigrams and because they have a high resting level (based on frequency), high frequency syllables would therefore rapidly activate syllable competitors. High frequency syllable neighbours then strongly compete with the target at the word level because they have a high resting level (based on lexical frequency, as in the original IA model). This explains the inhibitory effect of high HFSN compared to low HFSN in this condition. In this case, the net effect of syllable frequency is inhibitory. In the lowHFBN condition, syllables receive less activation so they activate the target representation and the syllabic neighbours' representations more slowly. At the same time, the target word (but not the syllabic neighbours) receives direct activation from the letter level. Thus, in this case, syllable activation toward the target word and its syllabic neighbours occurs after the target word has received orthographic activation, and therefore after the difference of activation between the target word and its higher frequency neighbours has been reduced, and even reversed. The syllable activation then increases the target word activation (producing a facilitatory effect), while the syllabic neighbours are not sufficiently activated to result in inhibition toward the target word (the inhibitory effect is cancelled). To sum up, the IAS model predicts that the net syllabic effect is facilitatory for low fre quency bigram words. This temporal lag assumption explains why a facilitation effect from syllabic neighbourhood was observed in the low-HFBN condition in Experiments $2 a$ and $b$. In addition, it should be noted that in the present study, the word targets had no higher frequency orthographic neighbours, so no lateral inhibition from orthographic competitors was supposed to occur (Grainger et al., 1989). Finally, the IAS model can also account for recent Wndings in the literature. The pure phonological priming effect reported by Alvarez et al. (2004) is consistent with the assumption of a direct letter-phonological syllable connection. An initial bigram is supposed to activate all the 
consistent phonological syllables, thus explaining why in Spanish a pseudoword (e.g., bi.rel) primes a target word that shares the same first phonological syllable (e.g., vi.rus). The direct letter-syllable connection also explains why the syllable effect reported by Doignon and Zagar (2005) with the illusory conjunction paradigm decreased or even disappeared when the syllable boundaries did not exactly match the bigram boundaries.

\subsection{Conclusion}

To summarise, we conclude that the phonological syllable is an important functional sublexical unit in French and that orthographic redundancy contributes to its influence. A modified IA-model incorporating connected letters and phonological syllables with a resting level based on frequency located between the letter and the word levels, the IAS model, has provided an adapted framework to interpret our data verbally. Future simulations should be run in order to assess this interpretation. Further implementation of the IAS model would also make it possible to obtain specific predictions of the model by running simulations.

\section{Acknowledgements}

We thank Heike Martensen and an anonymous reviewer for very helpful comments and suggestions on earlier versions of this article.

\section{References}

Adams, M. J. (1979). Models of word recognition. Cognitive Psychology, 11, 133-176.

Adams, M. J. (1981). What good is orthographic redundancy? In O. J. L. Tzeng \& H. Singer (Eds.), Perception of print: reading research in experimental psychology (pp. 197-221). Hillsdale, NJ: Erlbaum.

Alvarez, C. J., Carreiras, M., \& de Vega, M. (2000). Syllable-frequency eVffect in visual word recognition: Evidence of sequential-type processing. Psicologica, 21, 341-374.

Alvarez, C. J., Carreiras, M., \& Perea, M. (2004). Are syllables phonological units in visual word recognition? Language and Cognitive Processes, 19, 427-452.

Alvarez, C. J., Carreiras, M., \& Taft, M. (2001). Syllables and morphemes: Contrasting frequency effects in Spanish. Journal of Experimental Psychology: Learning, Memory, and Cognition, 27, 545-555.

Ashby, J., \& Rayner, K. (2004). Representing syllable information during silent reading: Evidence from eye movements. Language and Cognitive Processes, 19, 391-426.

Barber, H., Vergara, M., \& Carreiras, M. (2004). Syllable-frequency effects in visual word recognition: Evidence from ERPs. Cognitive Neuroscience and Neuropsychology, 15, 545-548. 
Brand, M., Rey, A., \& Peereman, R. (2003). Where is the syllable priming effect in visual word recognition? Journal of Memory and Language, 48, 435-443.

Carreiras, M., Alvarez, J. C., \& De Vega, M. (1993). Syllable frequency and visual word recognition in Spanish. Journal of Memory and Language, 32, 766-780.

Carreiras, M., Ferrand, L., Grainger, J., \& Perea, M. (2005). Sequential effects of phonological priming in visual word recognition. Psychological Science, 16, 585-589.

Carreiras, M., \& Perea, M. (2002). Masked priming effects with syllabic neighbours in a lexical decision task. Journal of Experimental Psychology: Human Perception and Performance, 28, 1228-1242.

Carreiras, M., \& Perea, M. (2004a). Naming pseudowords in Spanish: Effects of syllable frequency. Brain and Language, 90, 393-400.

Carreiras, M., \& Perea, M. (2004b). Effects of syllable neighbourhood frequency in visual word recognition and reading: cross-task comparisons. In L. Ferrand \& J. Grainger (Eds.), Psycholinguistique cognitive (pp. 231-249). Bruxelles: De Boeck.

Colé, P., Magnan, A., \& Grainger, J. (1999). Syllable-sized units in visual word recognition: evidence from skilled and beginning readers of French. Applied Psycholinguistics, 20, 507-532.

Content, A., Kearns, R. K., \& Frauenfelder, U. H. (2001). Boundaries versus onsets in syllabic segmentation. Journal of Memory \& Language, 45, 177-199.

Content, A., Meunier, C., Kearns, R. K., \& Frauenfelder, U. H. (2001). Sequence detection in pseudowords in French: Where is the syllable effect? Language and Cognitive Processes, 16, 609-636.

Content, A., Mousty, P., \& Radeau, M. (1990). BRULEX: Une base de données lexicales informatisée pour le français écrit et parlé. L’Année Psychologique, 90, 551-556.

Cutler, A., Mehler, J., Norris, D., \& Segui, J. (1986). The syllable's diVering role in the segmentation of French and English. Journal of Memory and Language, 25, 385-400.

Doignon, N., \& Zagar, D. (2005). Illusory conjunctions in French: The nature of sublexical units in visual word recognition. Language and Cognitive Processes, 20, 443-464.

Dominguez, A., de Vega, M., \& Cuetos, F. (1997). Lexical inhibition from syllabic units in Spanish word recognition. Language and Cognitive Processes, 12, 401-422. 
Ducrot, O., \& Todorov, T. (1972). Dictionnaire encyclopédique des sciences du langage. Paris: Seuil.

Ferrand, L., \& New, B. (2003). Syllabic length effects in visual word recognition and naming. Acta Psychologica, 113, 167-183.

Ferrand, L., Segui, J., \& Grainger, J. (1996). Masked priming of word and picture naming: The role of syllabic units. Journal of Memory and Language, 35, 708-723.

Finney, S., Protopapas, A., \& Eimas, P. D. (1996). Attentional allocation to syllables in American English. Journal of Memory and Language, 35, 893-909.

Frost, R. (1998). Toward a strong phonological theory of visual word recognition: True issues and false trails. Psychological Bulletin, 123, 71-99.

Gernsbacher, M. A. (1984). Resolving 20 years of inconsistent interactions between lexical familiarity and orthography, concreteness, and polysemy. Journal of Experimental Psychology: General, 113, 256-281.

Grainger, J., O’Regan, J. K., Jacobs, A. M., \& Segui, J. (1989). On the role of competing word units in visual word recognition: The neighborhood frequency effect. Perception \& Psychophysics, 45, 189-195.

Jacobs, A. M., Grainger, J., Rey, A., \& Ziegler, J. C. (1998). MROM-p: An interactive activation, multiple readout model of orthographic and phonological processes in visual word recognition. In J. Grainger \& A. M. Jacobs (Eds.), Localist connectionist approaches to human cognition (pp. 147-188). Hillsdale, NJ: Erlbaum.

Klein, M. (1993). La syllabe comme interface de la production et de la réception phonique. In B. Laks \& M. Plénat (Eds.), De Natura Sonorum (pp. 101-141). Saint-Denis: PUV.

Lukatela, G., Eaton, T., \& Turvey, M. T. (2001). Does visual word identification involve a phonemic level. Cognition, 78, B41-B52.

Mathey, S., \& Zagar, D. (2002). Lexical similarity in visual word recognition: The effect of syllabic neighborhood in French. Current Psychology Letters: Behavior Brain \& Cognition, 8, 107-121.

McClelland, J. L., \& Rumelhart, D. E. (1981). An interactive activation model of context effects in letter perception, Part 1: An account of basic Wndings. Psychological Review, 88, 375-407.

Mehler, J., Dommergues, J.-Y., Frauenfelder, U., \& Segui, J. (1981). The syllable's role in speech segmentation. Journal of Verbal Learning and Verbal Behaviour, 20, 298-305. 
New, B., Pallier, C., Ferrand, L., \& Matos, R. (2001). Une base de données lexicales du français contemporain sur internet: LEXIQUE. L'Année Psychologique, 101, 447-462.

Pallier, C., Sebastian-Gallés, N., Felguera, T., Christophe, A., \& Mehler, J. (1993). Attentional allocation within the syllable structure of spoken words. Journal of Memory and Language, 32, 373-389.

Perea, M., \& Carreiras, M. (1998). Effects of syllable frequency and syllable neighborhood frequency in visual word recognition. Journal of Experimental Psychology: Human Perception and Performance, 24, 134-144

Perea, M., Rosa, E., \& Gomez, C. (2002). Is the go/no-go lexical decision task an alternative to the yes/no lexical decision task. Memory and Cognition, 30, 34-45.

Plaut, D. C. (1999). A connectionist approach to word reading and acquired dyslexia: Extension to sequential processing. Cognitive Science, 23, 543-568.

Prinzmetal, W., Treiman, R., \& Rho, S. H. (1986). How to see a reading unit. Journal of Memory and Language, 25, 461-475.

Rapp, B. C. (1992). The nature of sublexical orthographic organization: The bigram trough hypothesis examined. Journal of Memory and Language, 31, 33-53.

Rouibah, A., \& Taft, M. (2001). The role of syllabic structure in French word recognition. Memory \& Cognition, 29, 373-381.

Rumelhart, D. E., \& McClelland, J. L. (1982). An interactive activation model of context effects in letter perception, Part 2: The contextual enhancement effect and some tests and extensions of the model. Psychological Review, 89, 60-94.

Sears, C. R., Hino, Y., \& Lupker, J. (1999). Orthographic neighbourhood effects in parallel distributed processing models. Canadian Journal of Experimental Psychology, 53, 220-229.

Sebastian-Gallés, N., Dupoux, E., Segui, J., \& Mehler, J. (1992). Contrasting syllabic effects in Catalan and Spanish. Journal of Memory and Language, 31, 18-32.

Seidenberg, M. (1987). Sublexical structures in visual word recognition: Access units or orthographic redundancy? In M. Coltheart (Ed.), Attention and Performance XII (pp. 245-263). Hillsdale, NJ: Erlbaum.

Seidenberg, M. S., \& McClelland, J. L. (1989). A distributed, developmental model of word recognition and naming. Psychological Review, 96, 523-568. 
Spoehr, K. T., \& Smith, E. E. (1973). The role of syllables in perceptual processing. Cognitive Psychology, 5, 71-89.

Taft, M. (1979). Lexical access via an orthographic code: The Basic Orthographic Syllabic Structure (BOSS). Journal of Verbal Learning and Verbal Behavior, 18, 21-39.

Taft, M. (1987). Morphographic processing: The BOSS re-emerges. In M. Coltheart (Ed.), Attention and Performance XII (pp. 265-279). Hillsdale, NJ: Erlbaum.

Taft, M. (1992). The body of the BOSS: Subsyllabic units in the lexical processing of polysyllabic words. Journal of Experimental Psychology: Human Perception \& Performance, 18, 1004-1014.

Taft, M., \& Forster, K. I. (1975). Lexical storage and retrieval of prefixed words. Journal of Verbal Learning and Verbal Behavior, 14, 638-647.

Taft, M., \& Forster, K. I. (1976). Lexical storage and retrieval of polymorphemic and polysyllabic words. Journal of Verbal Learning and Verbal Behavior, 15, 607-620.

Taft, M., \& Radeau, M. (1995). The influence of the phonological characteristics of a language on the functional units of reading: A study in French. Canadian Journal of Experimental Psychology, 49, 330-346.

Treiman, R. (1986). The division between onsets and rimes in English syllables. Journal of Memory and Language, 25, 476-491.

Treiman, R., \& Chafetz, J. (1987). Are there onset- and rime-like units in printed words? In M. Coltheart (Ed.), Attention and Performance XII (pp. 282-297). Hillsdale, NJ: Erlbaum.

van Heuven, W. J. B. \& Dijkstra, T. (2001). The semantic, orthographic and phonological interactive activation (SOPHIA) model. Paper presented at the XII ESCOP Conference. Edinburgh, September.

Vihman, M. M., DePaolis, R. A., \& Davis, B. L. (1998). Is there a "trochaic bias" in early word learning? Evidence from infant production in English and French. Child Development, 69, 935949. 
